\title{
Intracavernosal metaraminol for treatment of intraoperative penile erection
}

\author{
S.K. Tsai and C.Y. Hong ${ }^{1}$
}

\author{
Departments of Anaesthesiology and ${ }^{1}$ Medicine, Taipei Veterans General Hospital, Institute of Clinical \\ Medicine, National Yang-Ming Medical College, Taipei, Taiwan, ROC
}

\begin{abstract}
Summary: Four patients developed penile erection when regional anaesthesia was induced with spinal block. In another patient, penile erection developed during fentanyl-induced general anaesthesia. Injection of metaraminol into corpus cavernosum successfully achieved detumescence in all these patients. The dose of metaraminol ranged from 10 to $25 \mu \mathrm{g}$, much less than that required for the treatment of vasodilator-induced priapism. Intracavernosal injection of metaraminol is a simple, effective and safe method for immediate relief of intraoperative penile erection. It is most useful when urogenital operation would be delayed by penile tumescence.
\end{abstract}

\section{Introduction}

Intraoperative penile erection may render continuation of the surgical procedure impossible, especially in patients undergoing urogenital operation. While most of the reported cases were associated with spinal anaesthesia, ${ }^{1}$ it may also occur during general anaesthesia, most often when the penis is being prepared for urethral catheterization after induction of anaesthesia with high dose of fentanyl. ${ }^{2}$ Intravenous administration of ketamine,${ }^{2,3}$ physostigmine ${ }^{4}$ or ephedrine, ${ }^{5}$ inhalation of amyl nitrate, ${ }^{6}$ dorsal nerve block of penis, ${ }^{7}$ and topical application of nitroglycerine ${ }^{8}$ have been proposed for treatment. Such treatments are not without drawbacks, being either ineffective in some cases ${ }^{1,3,7}$ or complicated with cardiovascular side effects in others. ${ }^{2}$

Brindley found that injection of an alphaadrenergic stimulating agent such as metaraminol into the human corpus cavernosum penis may relieve priapism. ${ }^{9}$ This method is now widely practiced in impotent patients who develop priapism as a complication of pharmacologicallyinduced penile erection, in which a vasodilator such as papaverine or phentolamine is injected into the penis. ${ }^{10}$

We present 5 patients in whom intracavernosal injection of metaraminol successfully achieved detumescence during surgical operations.

Correspondence: Professor C.Y. Hong, M.D. (Taipei), Ph.D. (London)

Accepted: 22 May 1990

\section{Case reports}

Clinical summaries of these five patients are shown in Table I.

Penile erection was noticed before any surgical stimulus in the first four cases despite levels of sensory block from T8 to T11.

Patient 5 was a 54 year old, $56 \mathrm{~kg}$ man with atherosclerotic heart disease. On the day of coronary artery bypass surgery, general anaesthesia was induced with slow intravenous injection of fentanyl at a dose of $75 \mu \mathrm{g} / \mathrm{kg}$. Penile erection occurred while his penis was being prepared for urethral catheterization.

In all these cases, a small dose of metaraminol (Aramine, MSD) was injected intracavernosally at one side of the penile shaft through a 27 gauze needle. Complete resolution of penile tumescence was achieved within 2 minutes in every patient. Doses of metaraminol ranged from 10 to $25 \mu \mathrm{g}$, diluted in normal saline to a concentration of $100 \mu \mathrm{g} / \mathrm{ml}$. Blood pressure and heart rate which were measured immediately before and 3 minutes after metaraminol injection are shown in Table II. There were no significant changes. These parameters were followed up regularly during the operation. No adverse haemodynamic effect and no recurrent intraoperative penile tumescence were observed. The surgical procedures were carried out smoothly in every patient.

\section{Discussion}

Erection is a complex but coordinated event that involves vascular, nervous and psychogenic fac- 
Table I Effect of intracavernosal metaraminol on intraoperative penile erection

\begin{tabular}{lcllcc}
\hline $\begin{array}{l}\text { Case } \\
\text { no. }\end{array}$ & $\begin{array}{c}\text { Age } \\
\text { (years) }\end{array}$ & $\begin{array}{l}\text { Surgical } \\
\text { procedure }\end{array}$ & $\begin{array}{l}\text { Type of } \\
\text { anaesthesia }\end{array}$ & $\begin{array}{c}\text { Sensory } \\
\text { block }\end{array}$ & $\begin{array}{c}\text { Metaraminol } \\
\text { dose }(\mu \mathrm{g})\end{array}$ \\
\hline 1 & 34 & Ureteroscopy & Epidural & T8 & 25 \\
2 & 71 & TUR $^{*}$ & Spinal & T10 & 25 \\
3 & 65 & TUR $^{*}$ & Spinal & T9 & 15 \\
4 & 12 & Circumcision & Epidural & T11 & 10 \\
5 & 54 & CABG $^{\dagger}$ & Fentanyl & - & 15 \\
\hline
\end{tabular}

"Trans-urethral resection of prostate. ${ }^{\dagger}$ Coronary artery bypass graft.

Table II Blood pressure (BP) and heart rate (HR) immediately before and 3 minutes after metaraminol injection*

\begin{tabular}{lccccc}
\hline & \multicolumn{2}{c}{$B P(\mathrm{mmHg})$} & & \multicolumn{2}{c}{$H R$ (beats/minute) } \\
\cline { 2 - 3 } \cline { 5 - 6 } $\begin{array}{l}\text { nase } \\
\text { no. }\end{array}$ & Before & After & & Before & After \\
\hline 1 & $120 / 78$ & $134 / 66$ & & 80 & 92 \\
2 & $136 / 90$ & $130 / 90$ & & 83 & 72 \\
3 & $140 / 72$ & $128 / 76$ & & 87 & 87 \\
4 & $132 / 86$ & $130 / 84$ & & 76 & 78 \\
5 & $116 / 74$ & $120 / 74$ & & 88 & 90 \\
mean & $128.8 / 79.8$ & $128.4 / 78.0$ & & 82.8 & 83.8 \\
\pm s.d. & $\pm 10.3 / \pm 7.8$ & $\pm 5.2 / \pm 9.3$ & & \pm 4.9 & \pm 8.5 \\
\hline
\end{tabular}

"Neither BP nor HR was changed significantly $(P>0.05$, paired $t$-test).

tors. Both sympathetic neurones in the thoracolumbar cord and parasympathetic neurones in the sacral cord regulate the blood flow to corpus cavernosum which in turn leads to either flaccidity or tumescence of penis. " Autonomic imbalance between sympathetic and parasympathetic nervous system is generally considered as the underlying mechanism for intraoperative erection ${ }^{11}$ although local stimulation before complete sensory blockade $^{2}$ could also contribute to the problem.

In four of our cases penile erection developed when regional anaesthesia was induced with spinal block while in the last case it developed during fentanyl-induced general anaesthesia. Regardless of the type of anaesthesia as well as the cause of penile erection, complete resolution of penile tumescence could be achieved with intracavernosal injection of a small dose of metaraminol.

Brindley was the first one to report that intracavernosal injection of metaraminol causes shrink- age of the penis. The smallest dose that he tried on himself was $0.2 \mathrm{mg} .{ }^{10}$ However, when metaraminol was used for the treatment of iatrogenic priapism caused by prior injection of vasodilator, the effective dose of metaraminol ranged from 0.8 to $3 \mathrm{mg} .{ }^{9}$ A decrease of rigidity was not observed until 7 minutes after injection even in the most responsive case. Repeated injections of metaraminol, each injection given an hour or more apart, were required in some of his cases. ${ }^{9}$

The doses of metaraminol ranged from 10 to $25 \mu \mathrm{g}$ in our patients. In every case, penile erection was relieved within 2 minutes. Compared with the treatment of drug-induced priapism, management of intraoperative penile erection with metaraminol is relatively easy. It could be that in drug-induced priapism, intracavernosal smooth muscle cells have been blocked by vasodilators therefore a higher dose of metaraminol is required to reactivate them. ${ }^{9}$ Since the recommended dose of metaraminol for the treatment of hypotension is 2 to $10 \mathrm{mg},{ }^{12}$ it is unlikely that a single injection of this drug at a dose of 10 to $25 \mu \mathrm{g}$ can produce any systemic effect. No changes in blood pressure and heart rate were observed by us following intrapenile injection of metaraminol.

We conclude that intracavernosal injection of 10 to $25 \mu \mathrm{g}$ metaraminol is a simple, effective and safe method for immediate relief of intraoperative penile erection. It can be used in patients with either regional block or general anaesthesia. Unnecessary delay of surgical schedule can be prevented if more surgeons and anaesthetists are familiar with this technique. It should be admitted, however, that simple corporeal aspiration may also induce tumescence in some patients and penile erection on an operation table could be little more than an inconvenience; the decision to inject metaraminol should therefore not be taken lightly. 


\section{References}

1. Van Arsdalen, K.N., Chen, J.W. \& Smith, M.J.V. Penile erections complicating transurethral surgery. J Urol 1983, 129: 374-376.

2. Roy, R. Cardiovascular effects of ketamine given to relieve penile turgescence after high doses of fentanyl. Anesthesiology 1984, 61: 610-613.

3. Benzon, H.T., Leventhal, J.B. \& Ovassapian, A. Ketamine treatment of penile erection in the operating room. Anesth Analg 1983, 1983, 62: 457-458.

4. Ravindram, R.S., Dryden, G.E. \& Somerville, G.M. Treatment of priapism with ketamine and physostigmine. Anesth Analg 1982, 61: 705-707.

5. Miyabe, M. \& Namiki, A. Ephedrine for treatment of penile erection during spinal anesthesia. Anesth Analg 1988, 67: 1019-1020.

6. Nieder, R.M. Ketamine treatment of priapism. JAMA 1972 , 221: 195.
7. Welti, R.S. \& Brodsky, J.B. Treatment of intraoperative penile tumescence. J Urol 1980, 124: 925-926.

8. Synder, A.R. \& Ilko, R. Topical nitroglycerine for intraoperative penile turgescence. Anesth Analg 1987, 66: $1022-1023$.

9. Brindley, G.S. New treatment for priapism. Lancet 1984, ii: 220-221.

10. Brindley, G.S. Pilot experiments on the actions of drugs injected into the human corpus cavernosum penis. $\mathrm{Br} J$ Pharmacol 1986, 87: 495-500.

11. Lue, T.F., Zeineh, S.J., Schmidt, R.A. \& Tanagho, E.A. Neuroanatomy of penile erection: its relevance to iatrogenic impotence. J Urol 1984, 131: 273-280.

12. Weiner, $\mathrm{N}$. Norepinephrine, epinephrine and the sympathomimetic amines. In: Gilman, A.G., Goodman, L.S., Rall, T.W. \& Murad, F. (eds) The Pharmacological Basis of Therapeutics, 7th ed. Macmillan, New York, 1985, p. 170. 